\title{
Hacer de la ciencia una experiencia en nuestro idioma
}

\author{
Guadalupe Zamarrón Garza, \\ Alicia García Bergua y \\ Luci Cruz Wilson
}

\section{Resumen}

Luis Estrada, pionero de la divulgación de la ciencia en México pensaba, en 2002, que el internet era un lugar idóneo para las labores de la divulgación de la ciencia en el futuro, bajo la premisa de lograrlo de manera libre, creativa, seria y profunda. Como parte de su equipo y tras un largo periodo de trabajo como divulgadoras de la ciencia nos dimos cuenta de que quienes se educaran en esta actividad no sólo requerirían de una formación científica y conocimiento de los lenguajes de los medios de comunicación, sino del entrenamiento en el uso de herramientas literarias para permitir a nuestro idioma abarcar los difíciles y variados contenidos de la ciencia. Ésta es la razón por la que constituimos el Taller/Portal Cienciorama en 2012, un espacio principalmente universitario para escribir creativamente sobre ciencia, así como para dialogar y publicar artículos y noticias científicas accesibles. Pensamos que estas labores hacen posible crear y extender la cultura científica, que a su vez contribuye a la toma de decisiones relevantes para el futuro de la sociedad.

Palabras clave: divulgación, lenguaje ordinario, creatividad, ingenio, oficio literario, escritor, diálogo, discusión, reflexión, espíritu crítico, subversión.

\section{MAKE SCIENCE AN EXPERIENCE IN OUR LANGUAGE}

\begin{abstract}
In 2002, Luis Estrada, science communication pioneer in Mexico, thought that the internet was the ideal place for future work towards the popularization of science, premised on the possibility of achieving this in a free, creative, serious and profound way. As part of his team and after a long period working as science communicators we realized that this activity required not only a scientific training and knowledge of media languages, but also the training in literary tools that allowed our language to cover the difficult and varied contents of science. This is the reason why we set up the Cienciorama Workshop / Portal in 2012, a primordially academic space open for participants to write creatively about science, to dialogue and publish articles and accessible scientific news. We think these tasks make possible the creation and extension of scientific culture, which contributes to making relevant decisions for the future of society.
\end{abstract}

Key words: popularization, language, creativity, wit, literary skills, writer, dialog, argument, thoughtfulness, critical mind, subversion.

DOI: http://doi.org/10.22201/codeic.16076079e.2018.v19n2.a8 


\section{Guadalupe Zamarrón Garza}

Tiene estudios de física, pintura, música y realización cinematográfica en el Centro de Capacitación Cinematográfica en la UNAM. Desde el 2001 colabora en el Proyecto Cienciorama. Ha desarrollado principalmente en dos vertientes: editorial y audiovisual. Editorial: en las revistas Naturaleza y Chispa, principalmente. Coedición de libros sobre comunicación pública de la ciencia con universidades del país, cubanas, brasileñas y españolas. Audiovisual: Conducción y realización de la serie La Ciencia y Usted transmitida por canal 11, y programas documentales por Canal 4, ambos productos del Conacyt. Realización de películas en 16 mm de la AIC (HOY AMC) y audiovisuales sobre educación en la SEP. Estudio sobre el sistema mexicano de educación superior para la ANUIES. Miembro fundador de la Somedicyt y presidenta entre 1991-2. Gestora de los congresos nacionales de divulgación de la ciencia, organizadora del congreso I y II y del Premio Alejandra Jaidar organizados por la Somedicyt. Organizadora del Evento-Curso de Ciencias Planetarias con el Museo de la CFE y Somedicyt: pláticas de divulgación impartidas por el Físico Luis Álvarez, presentación y diálogo en los Institutos de Astronomía y Geofísica de la UNAM y el curso y las pláticas en el Museo de la CFE. Iniciadora del área de televisión del Conacyt. 1973. Labores técnico-académicas en CUPRA, CUCC, TV y la DGIA, de la UNAM. Actualmente (2017-18) es coordinadora del Proyecto Cienciorama que alberga la Dirección General de Divulgación de la Ciencia de la UNAM y auspicia la Sociedad Mexicana para la Divulgación de la Ciencia, SOMEDICYT.

\section{Alicia García Bergua}

Es escritora. Nació en la Ciudad de México el 9 de septiembre de 1954. Estudió la licenciatura de filosofía en la Facultad de Filosofía y Letras de la Universidad Nacional Autónoma de México. De 1975 a 1988 trabajó en la revista Naturaleza, de la que llegó a ser jefa de redacción, y en el Centro de Comunicación de la Ciencia de la UNAM, donde se formó para hacer divulgación científica con el grupo fundador de la divulgación científica en México dirigido por Luis Estrada. Fue editora en la primera etapa como revista del suplemento La Jornada Semanal, 1988-1991. Coordinadora de publicaciones del Instituto Nacional Indigenista, 1991-1993. Guionista y asistente de la Coordinación de Información del Noticiero Cultural 9:30 de Canal 22 desde su comienzo en 1993 hasta 1996. Editora de la revista Este País de 1996 a 2001 y asistente editorial de Scientific American- México de 2004 a 2006. Ha realizado gran cantidad de trabajo editorial y de traducción de textos especializados y de divulgación de la ciencia, además de algunos libros. Ha impartido cursos y talleres sobre poesía en la Universidad del Claustro de Sor Juana (2009 y 2010) y en la Sociedad General de Escritores de México (SOGEM) (2008 y 2017). Trabaja actualmente en la Dirección General de Divulgación de la Ciencia de la UNAM como editora e instructora del taller-portal de escritura creativa en divulgación científica Cienciorama, y como editora y escritora de textos de divulgación de la ciencia en la revista de ciencia para jóvenes ¿Cómo ves? Es autora de los libros de poesía Fatigarse entre fantasmas (Ediciones Toledo, 1991), La anchura de la calle (Conaculta, col. Práctica Mortal, 1996), Una naranja en medio de la tarde (Libros del Umbral/ Pablo Boullosa, 2005); Tramas (Cálamos-INBA-Conaculta, 2007), El libro de Carlos (Ed. Juan Malasuerte, 2007) y Ser y seguir siendo (editorial Textofilia 2013), del libro de ensayos Inmersiones (Dirección General de Publicaciones, UNAM, 2009) y de un libro de ensayos aún inédito La lucha con la zozobra. La libertad bajo palabra en México de cuatro poetas modernos: Villaurrutia, Owen, Cuesta y Paz y un libro de poemas inédito aún también, Salto y sueño. Ha sido miembro del Sistema Nacional de Creadores de México en los periodos 2001-2007, 2011-2013 y lo es actualmente.

\section{Luci Cruz Wilson}

Estudió biología en la Facultad de Ciencias de la UNAM. En 1982 se integró al Centro Universitario de Comunicación de la Ciencia de la UNAM dirigido por Luis Estrada. Como divulgadora de la ciencia ha trabajado en proyectos editoriales como autora o coautora de 28 libros de texto, de divulgación científica y diseño de juegos para niños (CONAFE, CONACULTA/ADN Editores, Santillana, Nuevo 
México, DGDC, ACMor, SEP). Ha ideado y realizado la coordinación editorial de las colecciones de libros para niños Salud para todos (ADN Editores/Instituto de Ciencia y Tecnología del DF) y ¿Qué te comes? (Academia de Ciencias de Morelos). Fue editora del boletín Salvia (INSP) y de la revista Pronatura. Ha participado en 23 proyectos museográficos, en las áreas de planeación, investigación documental e iconográfica (Margen Rojo, A.C.; Concepto M; Somedicyt), algunos de ellos son: Expo Lisboa -Exposición temporal- Entre Mares (1998); Museo de Historia Natural TAMUX, Cd. Victoria, Tamaulipas (2004); Exposición temporal Hábitat del Riesgo a la Sustentabilidad, Forum Monterrey (2007); Museo Centro de Interpretación Ecológica, Reserva de la Biósfera El Cielo, Tamaulipas (2010); Exposición temporal UNAM, Premio Príncipe de Asturias, Toledo, España (2010); Exposición temporal Paseo en Mapa, D.F. Antiguo Colegio de San Ildefonso (2010). Proyecto de remodelación, museografía y actualización de contenidos del Museo de Historia Natural de la Ciudad de México (2013). Ha participado en proyectos de televisión y video como guionista en series sobre ciencia y medio ambiente (TVUNAM, Filmoteca de la UNAM, Canal 11 y Canal 22). Fue Coordinadora general del programa de televisión Ciencia Hoy (TVUNAM/Canal 11). Desde 2012 participa como Coordinadora del Taller/Portal Cienciorama de la DGDC-UNAM.

\section{Una idea en marcha}

Desde que se inició el proyecto Cienciorama, a finales de 2002, y hasta el final de su primera etapa en 2012, la idea de Luis Estrada y su equipo fue, sobre todo instaurar una manera de hacer divulgación que consistía en dar a conocer los avances científicos más recientes de una manera confiable: proporcionando antecedentes, reflejando el gran dinamismo de la investigación científica, su espíritu y su proyección futura; además de crear un espacio de discusión y diálogo entre científicos, divulgadores, estudiantes y el público interesado en los avances de la ciencia. Para esto, Luis pensó que debían colaborar en el sitio los jóvenes estudiantes de ciencia e investigadores con ayuda de quienes editábamos los textos.

En 2003, para confeccionar la primera serie de materiales de Cienciorama se hicieron dos talleres con estudiantes universitarios de ciencia bajo la coordinación de Martín Bonfil y Susana Biro, divulgadores con formación científica.

En la segunda etapa de Cienciorama, que dio inicio a finales de 2012, existieron varias cuestiones que contribuyeron a intensificar algunos aspectos del trabajo, por mencionar algunas: el hecho de que internet se constituyó como un espacio para el diálogo a través de las redes sociales, y la necesidad de los colaboradores de expresarse literariamente; es decir, de usar con libertad y creatividad su propio lenguaje al escribir. Lo que descubrimos quienes reestructuramos Cienciorama como taller presencial en la segunda etapa, fue el deseo 
Diversidad de profesiones confluyen en Cienciorama.

En la fotografía, Edgar

Vargas (químico y actual administrador del portal y manejo de redes sociales), Fernando Vázquez (economista) y Laura Esquivel (bióloga). de los participantes que convocamos al taller, no sólo de escribir para compartir sus conocimientos, sino de aprender a hacerlo de una manera seria, profunda y profesional. Además, las reuniones dieron lugar a lo que se pueden considerar como tertulias literarias, en las que se habla de los temas y de los textos.

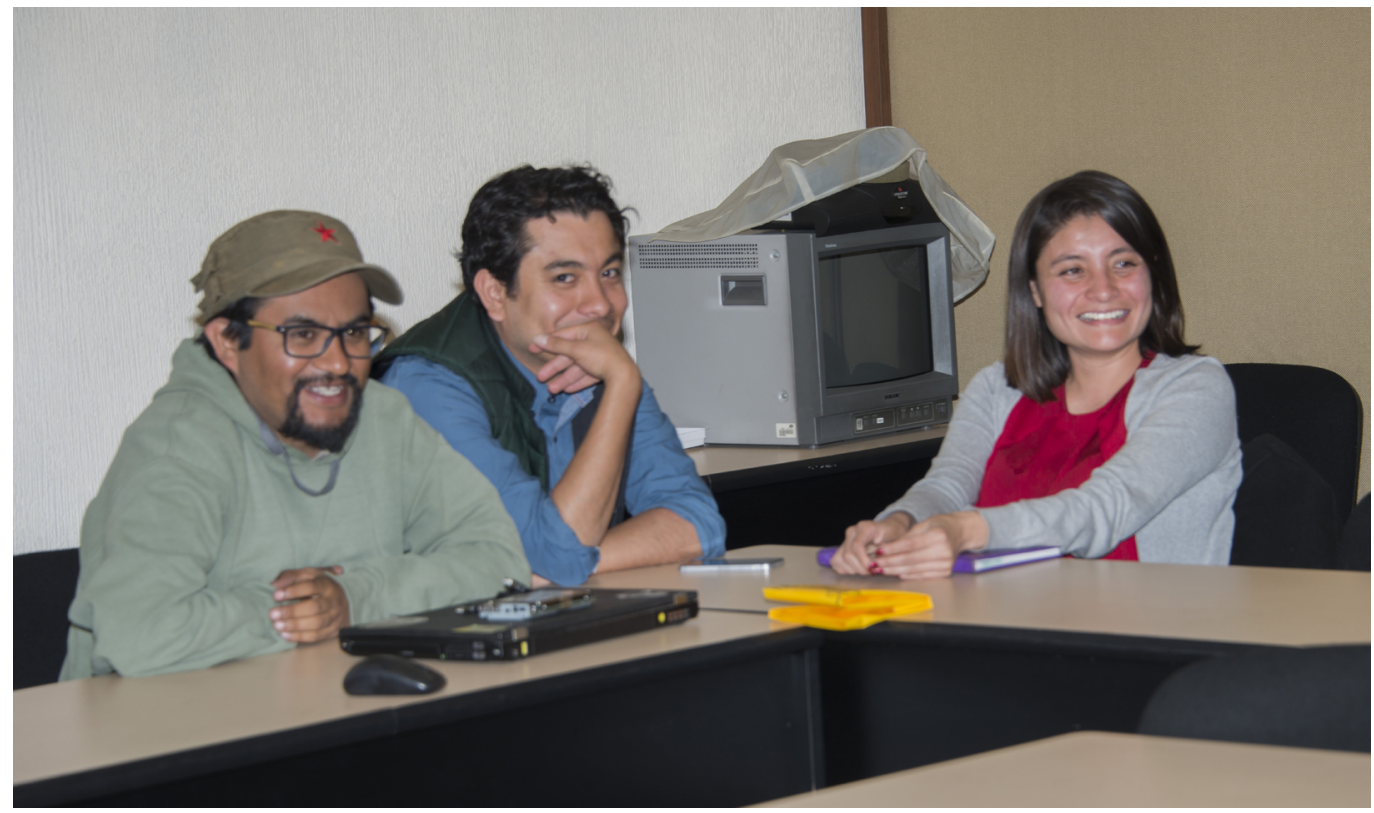

Así, Cienciorama se constituyó sobre todo como un taller de divulgación crítica y de escritura creativa en un espacio de diálogo, pues las coordinadoras/ editoras del proyecto partimos de la idea de que escribir no es redactar, escribir es pensar de manera ordenada y con el lenguaje preciso. Por eso les pedimos a los integrantes del taller un trabajo consciente de escritura en el que se atiendan todos los aspectos: la estructura con la cual se desarrollan las ideas, el modo en que éstas se narran y argumentan, y el lenguaje natural que se utiliza; así como el uso de metáforas y analogías, definiciones, explicaciones y comparaciones. Se vigila además que el contenido esté basado en trabajos de investigación muchas veces se trata de investigaciones en las que ellos mismos participan-, que las conclusiones e ideas se desprendan del texto y que éste, al igual que los textos literarios, sea autocontenido y suficiente para entender algo a grandes rasgos. A la vez tenemos interés en que los participantes utilicen su lengua con ingenio y creatividad y que cultiven los géneros literarios que deseen y que más se ajusten a lo que quieren expresar.

\section{La creatividad al escribir sobre ciencia}

Dentro del ámbito de la divulgación de la ciencia no deja de ser un tema polémico el de quiénes están en la mejor posición para trasladar los contenidos del lenguaje que utilizan los científicos en sus prácticas, a un lenguaje ordinario o 
Mariana Esther Martínez (biomédica) escribe artículos y noticias para Cienciorama. natural accesible a públicos más amplios. Para muchos, la respuesta es que son aquellos que tienen una formación científica; para otros, resulta dudoso pues muchas veces los científicos carecen de habilidades literarias o simplemente no las cultivan y tampoco manejan los métodos y técnicas de las ciencias de la comunicación. Aunque cada vez es más claro para los científicos que comunicar de manera más abierta los resultados de sus investigaciones los beneficia en el interior del mundo académico y da oportunidad, además, de acercar su conocimiento a un público más abierto e interesado en la ciencia. Sin embargo, en lo que todos coinciden es en que se requiere imaginación, ingenio y creatividad para trasladar con herramientas literarias los saberes de la ciencia a otros espacios donde se utiliza el lenguaje natural u ordinario. La divulgadora de la ciencia y escritora Ana María Sánchez dice que "tanto el quehacer científico como el literario son actividades intelectuales de creación", que bien pueden combinarse en el arte de difundir la ciencia. Bajo esta premisa en el Taller/Portal Cienciorama se estimula a los estudiantes-colaboradores a que lean textos clásicos de divulgación y a que desarrollen el oficio de escritores al explorar distintas formas de descripción y narración. Estas exploraciones han dado lugar a que muchos de los participantes desarrollen su modo de escribir y adquieran cada vez mayores capacidades de expresar por escrito los temas que les interesan. Ver, por ejemplo, el primer texto de Edgar Rosas Reyna "Rotavirus: pequeños individuos con grandes repercusiones" y su última colaboración "El Bueno, el malo y el mobiloma". O también el primero y el último de Natalia Martínez Ainsworth: "Rastreo de genes, del presente al pasado", y "Cuando las lagartijas ligan". Otro ejemplo significativo es el de Queletzu Paulina Aspra Polo, "Epigenética: el laberinto de los genes", el primero, y "Los hijos del lechero", el último. Otro ejemplo es el de Gerardo Martínez Avilés con su primer texto, "Estrellas binarias" y el último, "EEl principio antrópico".

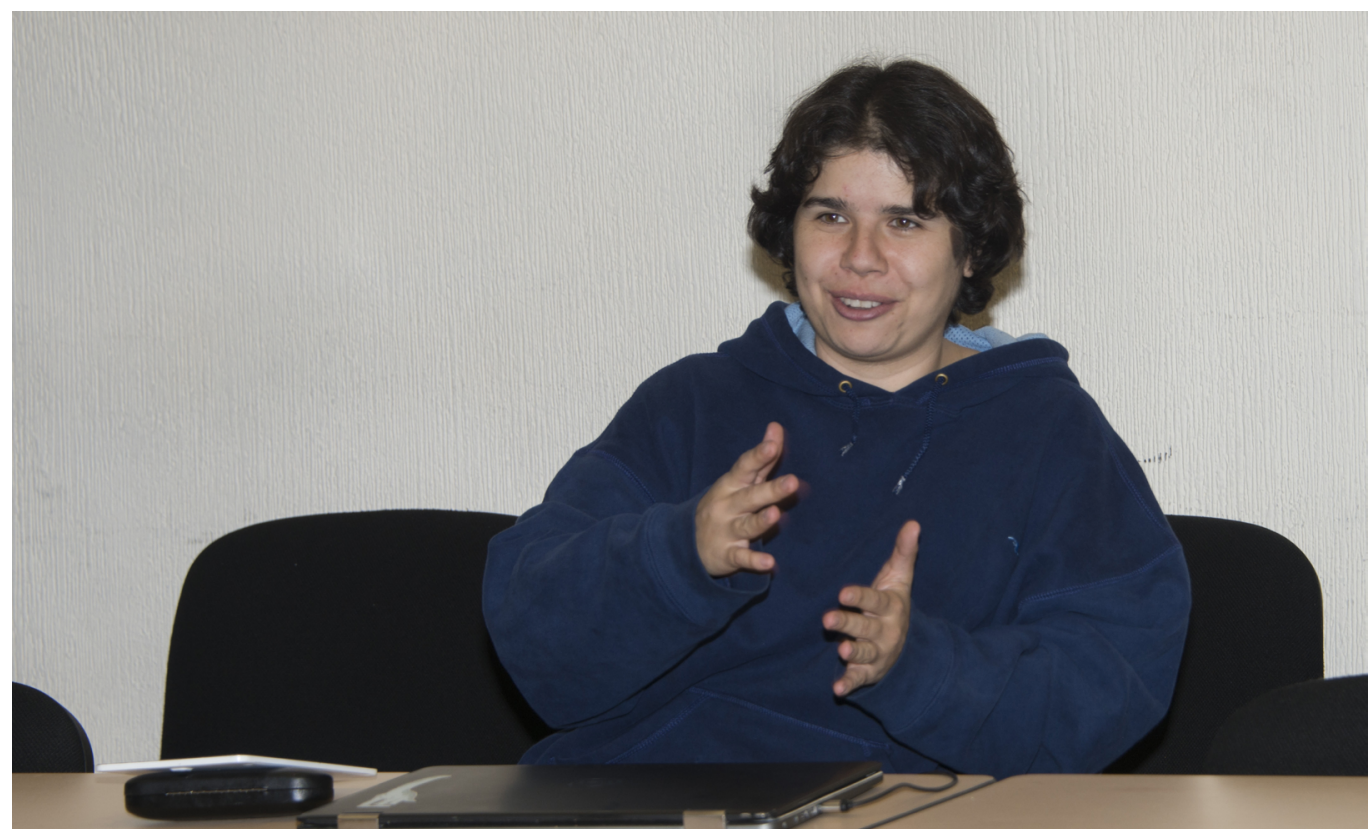




\section{La mejor cara de la subversión}

Uno de los objetivos del Taller/Portal Cienciorama es que sea una plaza pública donde se debata y reflexione libremente sobre temas científicos y tecnológicos, y además se hable de las implicaciones sociales, económicas y políticas de muchos temas. Hace algunos años -anteriores al invento del control remoto de la televisión- la gente veía canales. Después de la aparición del control remoto la gente empezó a ver programas. Antes del gran auge de las redes sociales, la gente visitaba sitios o portales, y ahora se entera de sus contenidos a través de las visitas a las redes sociales o de alertas informativas enviadas desde muy diversos orígenes. Por esta razón la discusión externa sobre los mate-
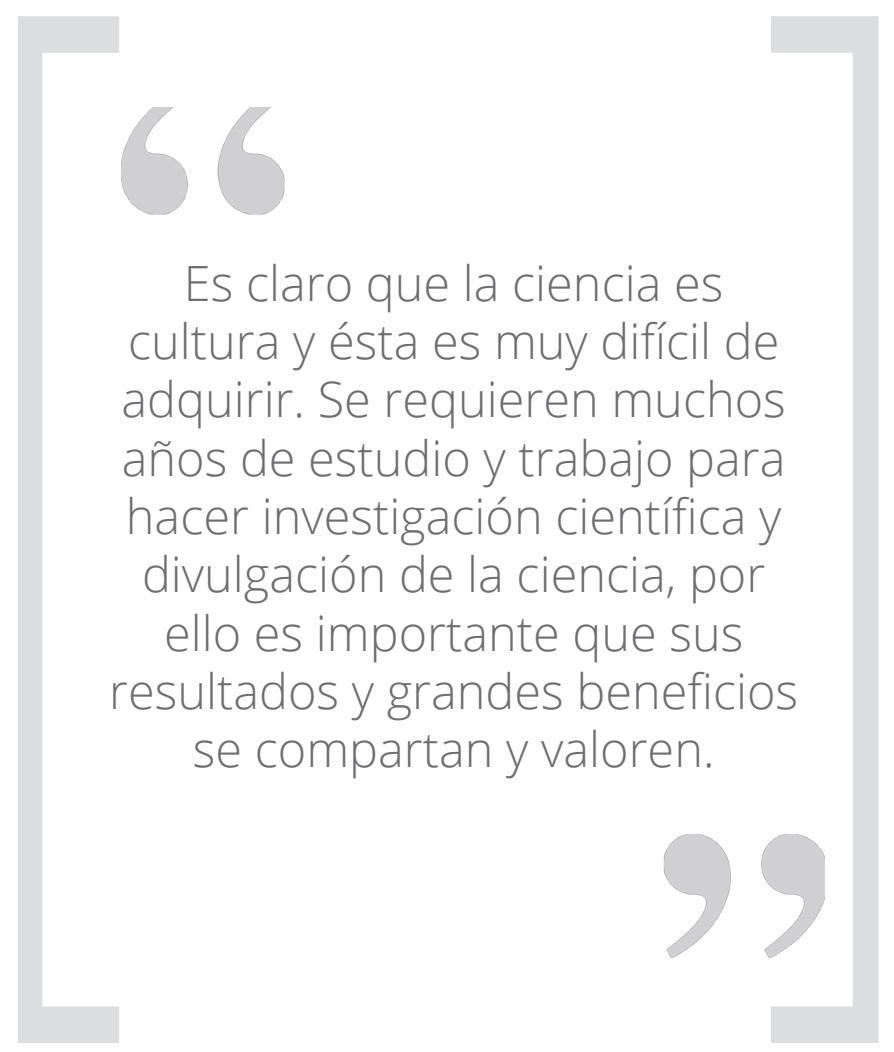
riales surge en las redes, principalmente Facebook, a donde se "mudó" la plaza pública. Aunque, por un lado y afortunadamente, la oferta informativa de divulgación científica es muy amplia, por otro, y desafortunadamente, resulta fácil extraviarse en el infinito universo de información que ofrece internet. Pero estamos convencidas de que un público lector con cultura científica sabrá la influencia que tienen la ciencia y la tecnología en su cotidianidad y en el desarrollo de una nación. Se requiere cada vez más de un público informado y participativo en temas cruciales como el cambio climático, la factibilidad del uso de organismos genéticamente modificados, el desarrollo de la inteligencia artificial o el delgado filo por el que se mueve la bioética, entre muchos otros. El conocimiento científico posibilita la capacidad de generar alternativas en diversos órdenes de la vida social. La confiabilidad y el espíritu crítico de los materiales del portal Cienciorama pueden facilitarle a la audiencia una mayor participación en la toma de decisiones y en la construcción de la vida democrática de México, esto es, la mejor cara de la subversión.

\section{Un proyecto colectivo}

Cienciorama es un proyecto colectivo, aunque las coordinadoras/editoras son las responsables directas, el proyecto no funciona verticalmente; todos en Cienciorama trabajamos desde 2013 y anteriormente desde 2002, con el objetivo común de que se escriban buenos textos de divulgación científica. Además, sabemos que un buen escrito es también un buen inicio para seguir formas y rutas muy distintas, desde constituir libros y revistas a ser la base de guiones videográficos, radiofónicos, museográficos o de entrevistas. 
Al desarrollar los textos para el Taller/Portal Cienciorama, los estudiantes/ colaboradores hacen mucha investigación documental que queda registrada en las bibliografías de cada artículo y esto convierte a Cienciorama también en un medio idóneo para buscar libros y artículos sobre distintos temas. Aunque la mayoría de los colaboradores de Cienciorama no se harán escritores científicos profesionales, hay quienes han hallado en la escritura una segunda vocación. El taller es también una forma de que futuros investigadores aprendan a comunicar ideas en sus proyectos, tesis y presentaciones de trabajos. Por ejemplo, el Dr. Miguel Ángel Martínez C., del Taller de Física de Radiaciones 2 de la Facultad de Ciencias de la UNAM envió un mensaje a Cienciorama que dice: "La participación de mi estudiante en el Taller/Portal Cienciorama le permitió mejorar notablemente sus habilidades de escritura. Y además de preparar su tesis de licenciatura colaboró en la escritura de un manual que será editado por la Facultad de Ciencias".

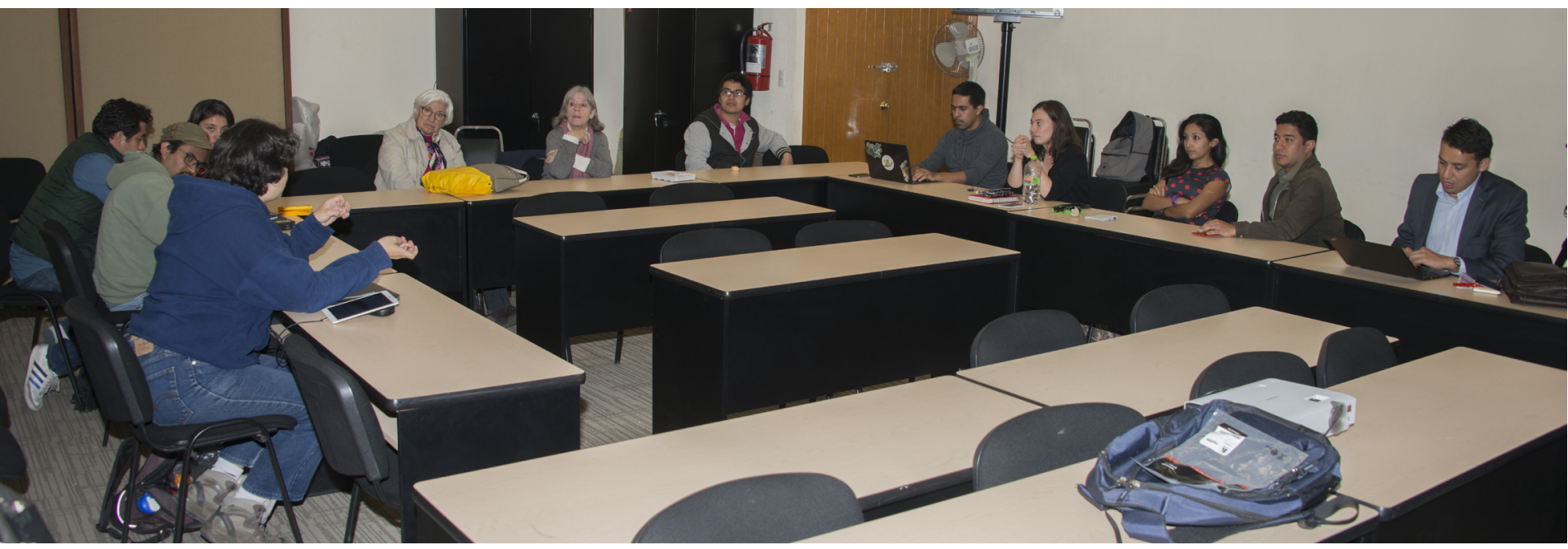

\section{Futuro para Cienciorama}

Lo que esperamos en Cienciorama es formar personas que serán parte de la sociedadl y del ámbito de la investigación científica, de la educación o de la comunicación, para que divulguen la ciencia de manera seria, responsable, amable, y que su mensaje llegue a la mayor cantidad de gente posible. Esperamos que realicen un ejercicio permanente del conocimiento racional fundado en la crítica, puesto que el saber, como bien público, no puede usarse como mercancía. Esto es fundamental en un mundo donde el conocimiento científico es una herramienta de sobrevivencia, incluso para aquellos que no se dedican a él. Es claro que la ciencia es cultura y ésta es muy difícil de adquirir. Se requieren muchos años de estudio y trabajo para hacer investigación científica y divulgación de la ciencia, por ello es importante que sus resultados y grandes beneficios se compartan y valoren. En Cienciorama estamos creando el espacio idóneo para 
ello y dependerá de sus participantes que se continúe divulgando la ciencia de una manera libre, profunda y crítica, pues ello redunda en la propia investigación que se alimenta también de las buenas ideas de la gente.

Estamos apenas sentado las bases de ese espacio de comunicación de la ciencia para el mundo hispanohablante que crecerá y se transformará en manos de las siguientes generaciones.

Agradecemos a Arturo Orta la obtención de las fotografías del Taller.

\section{Referencias}

- Gil Antón, Manuel (5 de octubre de 2001). La ciencia como elemento incómodo de la cultura", Mesa redonda, Seminario de Cultura Mexicana.

* Sara E. Brownell,1 Jordan V. Price,2 and Lawrence Steinman3. (2013). Science Communication to the General Public: Why We Need to Teach Undergraduate and Graduate Students this Skill as Part of Their Formal Scientific Training. octubre 2016, de J Undergrad Neurosci Educ Sitio web: https://www.ncbi.nlm.nih.gov/ pmc/articles/PMC3852879/

* KImberly Collins, David Shiffman y Jenny Rock (15 de octubre de 2013). "How Are Scientists Using Social Media in the Workplace?"Journal of Undergraduate Neuroscience Education, publicado en línea .

* Sánchez, Ana María (2000). La Divulgación de la ciencia como literatura, Dirección General de Divulgación de la Ciencia, UNAM, col. Divulgación para divulgadores, México.

\section{Conferencias}

- Luis Estrada (2007), "LA UNAM y yo".

* Luis Estrada (2009), "La comunicación de la ciencia".

* A. Mondragón (2007), "Luis Estrada".

\section{Cómo citar este artículo}

* Cruz Wilson, L., García Bergua, A., y Zamarrón Garza, G. (2018). Hacer de la ciencia una experiencia en nuestro idioma. Revista Digital Universitaria (RDU). Vol. 19, núm. 2 marzo-abril. DOI: http://doi.org/10.22201/codeic.16076079e.2018.v19n2.a8. 